PII: S0045-6535(97)00357-3

\title{
ALIPHATIC ALDEHYDES AND ALLETHRIN IN MOSQUITO-COIL SMOKE
}

\author{
Juei-Yun Chang, Jia-Ming Lin*
}

\author{
Institute of Environmental Health, College of Public Health, National Taiwan University. Room 1451, No. 1, \\ Jen Ai Road, 1st Sec., Taipei, Taiwan, R.O.C. \\ (Received in Japan 22 April 1997; accepted 6 August 1997)
}

\begin{abstract}
Presence of aliphatic aldehydes and allethrin in the smoke produced by two brands of mosquito-coil was determined by high performance liquid chromatography. It was observed that burning mosquito-coil produces a greater amount of formaldehyde, acetaldehyde and acrolein in the gaseous phase, whereas lesser amount of particulate-bounded alkehydes. Aldehydes bounded in particulates were, however, enriched in terms of concentration. Allethrin was found to occur only in particulates of 0.1-1.0 $\mu \mathrm{m}$ size. The results reveal that allethrin may not be capable of attacking the mosquitoes effectively. (C) 1997 Elsevier Science Ltd

\section{INTRODUCTION}

The mosquito-coil is a commercially available product for fumigating mosquitoes, and is widely used in Asia. The active ingredient of a mosquito-coil is pyrethrin or synthetic pyrethroid, which accounts for about $0.2 \%$ by weight. The remaining components are dye and filler such as wood dust and coconut flour. The $d$-allethrin is one of the most popular ingredients used in formulating a mosquito-coil. Upon burning mosquito-coil, allethrin and 46 organic compounds have been detected in generated smoke [1].

Exposure to mosquito-coil smoke leads to asthma and persistent wheeze in humans [2]. It also results in a focal deciliation of the tracheal epithelium, inflammation or metalplasia of epithelial cells, damage of liver tissues, intercellular fibrosis of lung and morphological alterations of the alveolar macrophages of the exposed rats $[3 ; 4 ; 5 ; 6]$. There are some reports indicating chromosome aberrations effects in rats $[7 ; 8]$.

The attacking effect of particulate-bounded insecticides mainly depends on the size of particulate. The bigger the particulate size is, the easier it is for the particulate to bombard the insect's body, while smaller the particulate size is, longer is the time that particulate sustains in air. Thus, the size of particulates for most effectively attacking mosquitoes is around $30 \mu \mathrm{m}[9]$.

In this paper, we investigated allethrin in both gaseous phase as well as particulate phase as present in mosquito-coil smoke. In addition, aliphatic aldehydes were also investigated, since they were observed to be present in most of the combustion products [10] and their biological effects have been commonly discussed. 
Formaldehyde is known to cause headache, nausea, vomiting, diarrhea, irritating upper respiratory tract, effecting neurobehavior, eyes burning, skin stinging, and fatigue $[11 ; 12]$. Formaldehyde is also known to induce squamous carcinomas and polypoid adenomas in the nasal cavity of rats $[13 ; 14]$, and is a suspected human carcinogen. Acetaldehyde was found to be cytotoxic and carcinogenic to nasal cavity of rats [15]. Acrolein exposure results in alterations of plasma membrane-dependent transport in pulmonary artery endothelial cells [16]

\section{MATERIAL AND METHOD}

The study subjects comprised of two brands of mosquito-coil, Viz. Er-Yi and Bay-Gon containing $0.25 \%$ and $0.2 \%$ of allethrin, respectively. Each coil was cut off in a $2 \mathrm{~cm}$ long piece, weighing about $0.25-0.35 \mathrm{~g}$, and was fixed in a holder kept in a $146.3 \mathrm{~L}$ burning chamber. The burning chamber was constructed by using polypropylene, as shown by the schematic aiagram in figure 1. Purified air, at a flow ate of $3.5 \mathrm{~L} / \mathrm{min}$, was lead into the chamber for 60 minutes and the relative humidity $(50 \%)$ and temperature $\left(20^{\circ} \mathrm{C}\right)$ were regulated by the Flow-Temperature Humidity Control System (HCS-301, Miller Nelson Research, USA) prior to burning a mosquito-coil.

The purified air source was closed after the above mentioned atmospheric conditions were reached, and then the mosquito-coil was ignited by a nickle chrome wire which was controlled by a voltage-regulator. Samples were collected immediately after the mosquito-coil was burned out. A glass fiber filter $(25 \mathrm{~mm}, 1 \mu \mathrm{m}$, SKC, USA) in an IOM sampler (stainless steel, Cat. No. 225-76, SKC, USA) was utilized for cnllecting the inhaled particulate mass at a flow rate of $2 \mathrm{~L} / \mathrm{min}$ for 10 minutes. A Sep-Pak DNPH-silica cartridge (Part No. 37500 , Millipore, USA) was used for collecting the gaseous samples at a flow rate of $0.4 \mathrm{~L} / \mathrm{min}$, for 10 minutes. The total particulates were also collected in a membrane filter (37 mm, Cat. No. 225-5, SKC, USA) at flow rate of $1 \mathrm{~L} / \mathrm{min}$, in accordance with the NIOSH 7400 method [17], and further treated to make them transparent for counting and sizing through an Image Analysis System (PC-meter, Ham-Jar, Taiwan) equipped with a microscope (Alphaphot-2 YS2, Nikon, Japan).

Initially, the net weight of particulates collected in a glass fiber filter was obtained by weighting them, then the filter was inserted into a $25 \mathrm{~mL}$ bottle containing $5 \mathrm{~mL}$ solution of $0.025 \mathrm{~mL}$ 2,4-dinitrophenyl hydrazine (DNPH, Art. 3081, Merck, USA) in $1 \mathrm{~mL}$ acetonitrile (BDH, Hipersolv, England), and was further extracted in an ultrasonic bath (Super RK 156BH, Sonorex, Germany) for about 30 minutes. The gaseous sample collected by the Sep-Pak DNPH silica cartridge was slowly eluted with $5 \mathrm{~mL}$ acetonitrile. Extractant and eluent were both prepared for HPLC analysis of allethrin, formaldehyde, acetaldehyde and acrolein.

For analyzing aldehyde-DNPH, standard material (TK151, the THETA Corp.) was used to prepare a series of standard solutions (SD). 4-fluorobenzonitrile (46680, Fluka, Switzerland), which serves as an internal standard (IS) was added to the standard solution as well as the samples. The calibration curve for each aldehyde was obtained by plotting the concentration of standard solution versus the area ratio of SD/IS. For carrying out the analysis of allethrin, standard solutions were prepared by using allethrin standard $(100 \%$, 


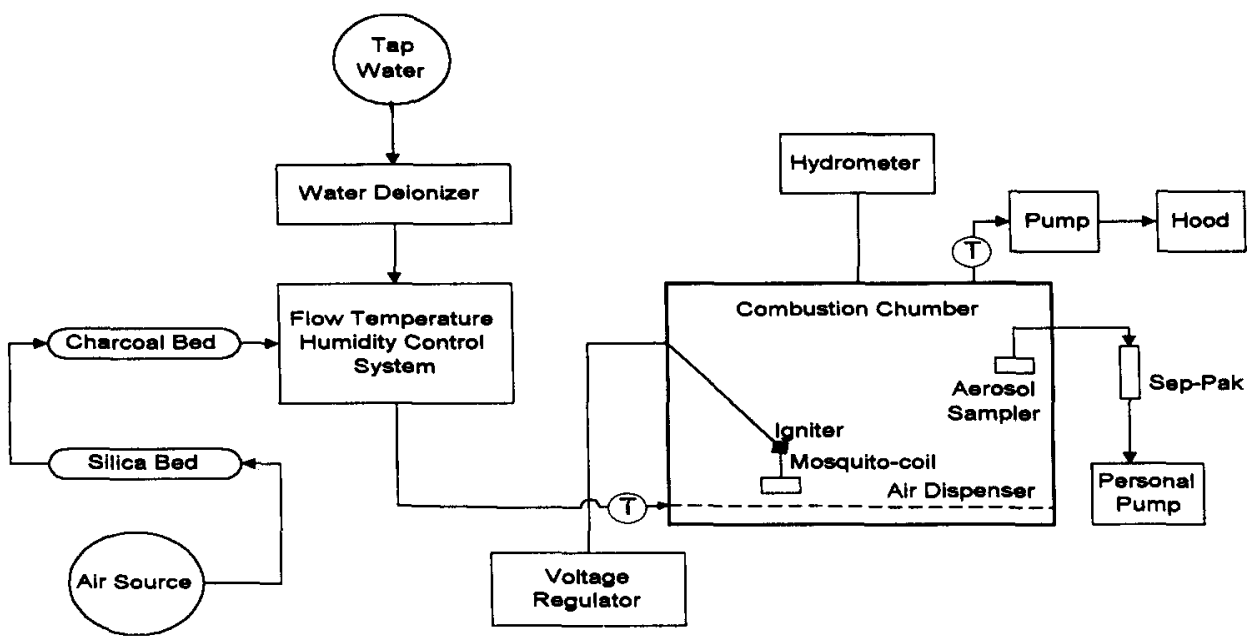

Figure 1. Schematic diagram of the flow system for generating and sampling mosquito-coil smoke

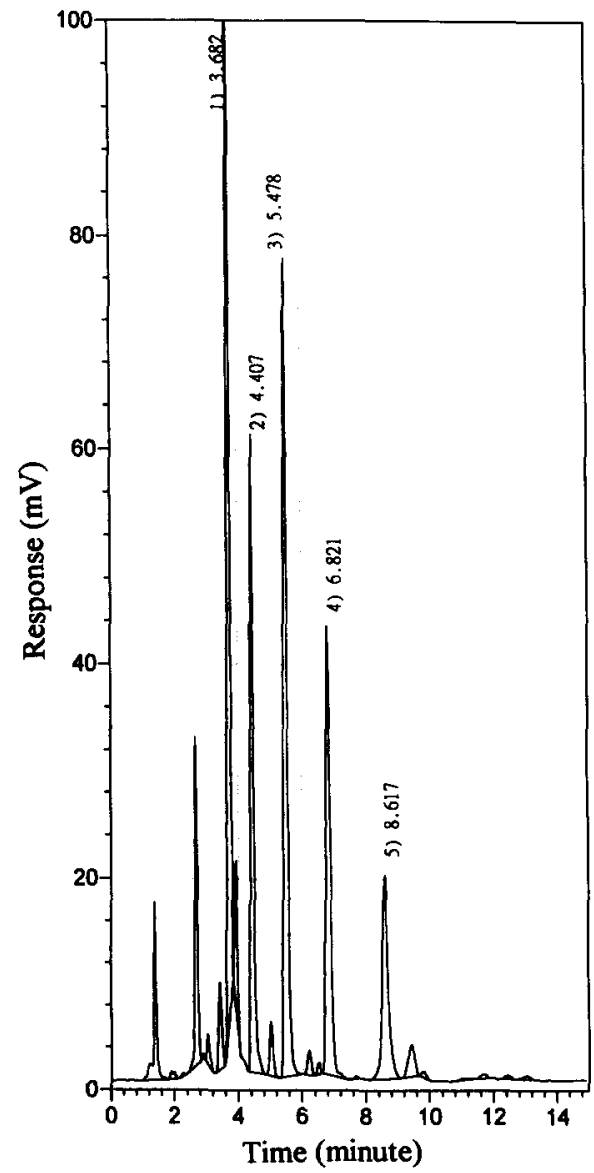

(1) 2,4-dinitrophenyl hydrazine (2,4-DNPH)

(2) 4-fluorobenzonitrile (internal standerd)

(3) formaldehyde-DNPH

(4) acetaldehyde-DNPH

(5) acrolein-DNPH

Figure 2. The HPLC chromatogram of the DNPH derivatives of aldehydes in gaseous phase 


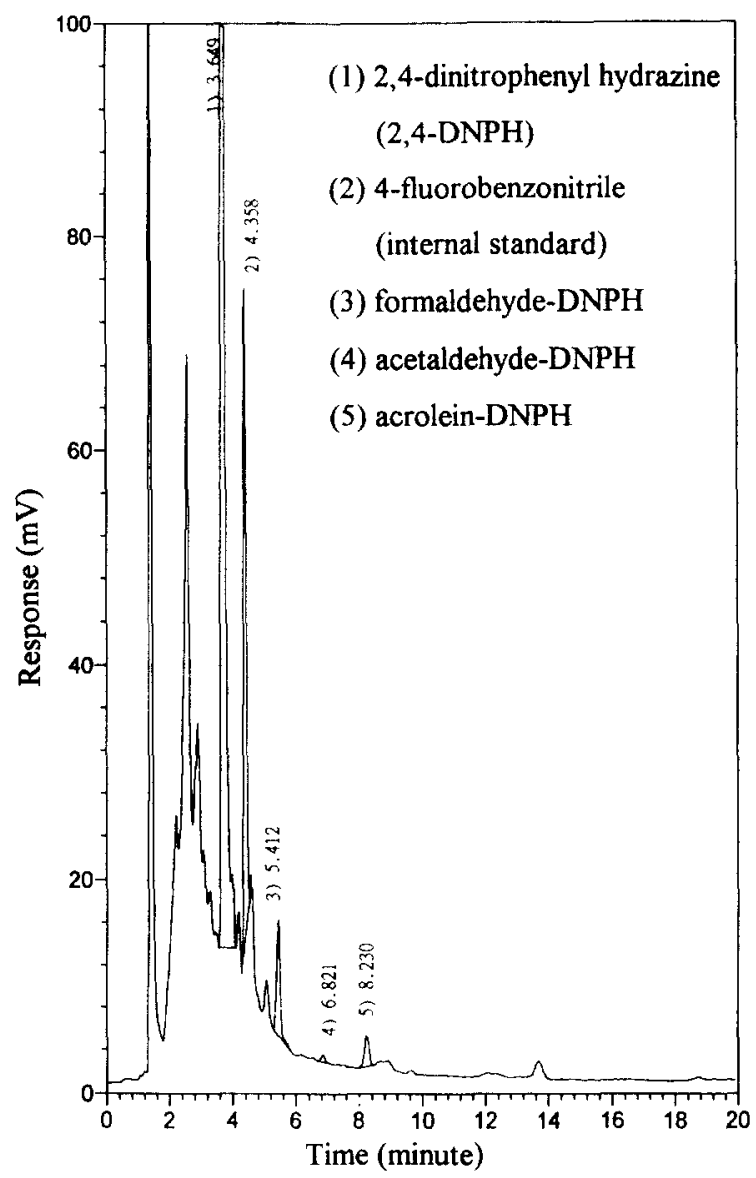

Figure 3. HPLC chromatogram of the DNPH derivatives of aldehydes in the particulate phase

Sumitomo, Japan) and the calibration curve was obtained by plotting the concentration of allethrin versus peak area of allethrin.

The aldehyde derivatives of DNPH were quantified by a high performance liquid chromatograph (Model 590, Waters, USA) equipped with a UV detector (Model 441, Waters, USA) operating at $254 \mathrm{~nm}$. The reverse phase column (Lichrospher $100 \mathrm{RP}-18,5 \mu \mathrm{m}, 250 \times 4 \mathrm{~mm}$, Merck, USA) was applied to the mobile phase of acetonitrile/deionized water (6/4) at a flow rate of $1 \mathrm{~mL} / \mathrm{min}$. A high performance liquid chromatograph (PU-980, Jasco, Japan) equipped with a UV/VIS detector (UV975, Jasco, Japan) operating at $225 \mathrm{~nm}$ was employed for analyzing allethrin. The column used was Envrio Sep-PP $(125 \times 3.2 \mathrm{~mm}$, Phenomenex, USA). The mobile phase was acetonitrile/deionized water (7/3) and was run at a flow rate of 1 $\mathrm{mL} / \mathrm{min}$. 
Table 1. Quantification of aldehydes and allethrin in both gaseous and particulate phases in the smoke of mosquito-coil.

\begin{tabular}{|c|c|c|}
\hline \multirow[b]{2}{*}{ Item of observation } & \multicolumn{2}{|c|}{ Result from the smoke of mosquito-coil } \\
\hline & $\operatorname{Er}-\mathrm{Yi}(\mathrm{n}=4)$ & Bay-Gon $(n=8)$ \\
\hline \multicolumn{3}{|c|}{ Gaseous aldehydes and allethrin } \\
\hline \multicolumn{3}{|c|}{ Conc. normalized, $\mathrm{ppm} / \mathrm{g}_{\mathrm{b}}{ }^{(1)}$} \\
\hline formaldehyde & $10.9 \pm 1.5^{(2)}$ & $21.3 \pm$ \\
\hline acetaldehyde & $7.4 \pm 0.6$ & $7.9 \pm$ \\
\hline acrolein & $4.0 \pm \quad 1.2$ & $5.0 \pm$ \\
\hline total aldehyde & $22.3 \pm 2.4$ & $34.2 \pm$ \\
\hline allethrin & $\mathrm{ND}^{(3)}$ & ND \\
\hline \multicolumn{3}{|l|}{ Yield, $\mu g / g_{b}$} \\
\hline formaldehyde & $2025.0 \pm 281.4$ & $3922.7 \pm 566.0$ \\
\hline acetaldehyde & $2030.9 \pm 158.7$ & $2147.8 \pm 221.2$ \\
\hline acrolein & $1423.7 \pm 453.9$ & $1747.1 \pm 255.1$ \\
\hline total aldehyde & $5497.6 \pm 666.4$ & $7817.6 \pm 859.8$ \\
\hline allethrin & ND & ND \\
\hline \multicolumn{3}{|c|}{ Particulate-bounded aldehydes and allethrin } \\
\hline \multicolumn{3}{|c|}{ Conc. observed, $\mu \mathrm{g} / \mathrm{g}_{\mathrm{p}}^{(4)}$} \\
\hline formaldehyde & $798.0 \pm 559.7$ & $329.0 \pm 291.2$ \\
\hline acetaldehyde & $87.5 \pm \quad 8.0$ & $107.3 \pm \quad 38.1$ \\
\hline acrolein & $334.4 \pm \quad 36.8$ & $349.5 \pm 116.5$ \\
\hline total aldehyde & $1219.9 \pm 569.2$ & $664.2 \pm 405.6$ \\
\hline allethrin $\left(\mathrm{mg} / \mathrm{g}_{\mathrm{p}}\right)$ & $29.1 \pm \quad 1.1$ & $15.1 \pm \quad 1.3$ \\
\hline \multicolumn{3}{|l|}{ Conc. nornnalized, $\mu \mathrm{g} / \mathrm{g}_{\mathrm{p}} / \mathrm{g}_{\mathrm{b}}$} \\
\hline formaldehyde & $2749.4 \pm 2146.1$ & $938.7 \pm 755.0$ \\
\hline acetaldehyde & \multirow{2}{*}{$\begin{array}{l}295.1 \pm 40.4 \\
1135.3 \pm 229.7\end{array}$} & $307.7 \pm 96.2$ \\
\hline acrolein & & $1027.7 \pm 335.5$ \\
\hline total aldehyde & $4180.4 \pm 2287.4$ & $1926.0 \pm 1073.5$ \\
\hline allethrin, $\mathrm{mg} / \mathrm{g}_{\mathrm{p}} / \mathrm{g}_{\mathrm{b}}$ & $98.4 \pm \quad 13.3$ & $44.7 \pm \quad 6.7$ \\
\hline Yield, $\mu \mathrm{g} / \mathrm{g}_{\mathrm{b}}$ & & \\
\hline formaldehyde & $45.4 \pm \quad 32.1$ & $10.3 \pm \quad 6.5$ \\
\hline acetaldehyde & $5.1 \pm \quad 0.7$ & $4.0 \pm \quad 1.4$ \\
\hline acrolein & $19.3 \pm$ & $11.9 \pm \quad 3.6$ \\
\hline total aldehyde & $69.8 \pm \quad 32.3$ & $21.9 \pm 10.4$ \\
\hline allethrin & $1677.7 \pm 101.3$ & $525.1 \pm 91.5$ \\
\hline
\end{tabular}


Simulated atmospheric condition: $19.5-21.2{ }^{\circ} \mathrm{C}, \mathrm{RH} 49-53.3 \%$

${ }^{(1)} \mathrm{g}_{\mathrm{b}}$ : per gram of burning material

${ }^{(2)}$ Mean $t$ S.D.

${ }^{(3)} \mathrm{ND}$ : not detectable; limit of detection: $1.75 \mu \mathrm{g} / \mathrm{mL}$

${ }^{(4)} g_{p}$ : per gram of particulate

\section{RESULTS AND DISCUSSION}

The HPLC chromatograms of DNPH derivatives of aliphatic aldehydes found in both the gaseous as well as particulate samples are presented in figures 2 and 3. On the basis of retention time, relative to internal standard and authentic aldehyde-DNPH spiking experiment, formaldehyde, acetaldehyde, and acrolein were identified in both gaseous and particulate samples collected from the smoke of mosquito-coil.

As tabulated in table 1, burning one gram of Er-Yi mosquito-coil generated $2025.0 \mu \mathrm{g}$ formaldehyde, $2030.9 \mu \mathrm{g}$ acetaldehyde and $1423.7 \mu \mathrm{g}$ acrolein in gaseous phase, and corresponding $45.4 \mu \mathrm{g}, 5.1 \mu \mathrm{g}$, and $19.3 \mu \mathrm{g}$ in particulate phase. Whereas, burning one gram of Bay-Gon mosquito-coil produced $3922.7 \mu \mathrm{g}$ formaldehyde, $2147.8 \mu \mathrm{g}$ acetaldeinyde, and $1747.1 \mu \mathrm{g}$ acrolein in gaseous phase, and corresponding $10.3 \mu \mathrm{g}$, $4.0 \mu \mathrm{g}$, and $11.9 \mu \mathrm{g}$ in particulate phase. A greater amount of aldehyde was observed to occur in gaseous phase, while most part of gaseous aldehydes was noted to be formaldehyde. The particulate-bounded aldehydes only accounted for a small portion of the total aldehydes. Further, it was also noticed that particulate-bounded acetaldehyde was of least amount. In addition, the aldehydes bounded in particulates were enriched in terms of concentration, although yields of particulate-bounded aldehydes were less than those of gaseous aldehydes. In comparison to the Er-Yi mosquito-coil, the Bay-Gon mosquito-coil showed a greater yield of gaseous aldehydes and lesser yield of particulate-bounded aldehydes. This difference is likely due to the different fillers used in these mosquito-coils.

The mass concentration and number concentration for particulates were found to be $117.63 \mathrm{mg} / \mathrm{m}^{3}$ and $3.7 \times 10^{10}$ particles $/ \mathrm{m}^{3}$, respectively, for Er-Yi mosquito-coil, whereas $80.43 \mathrm{mg} / \mathrm{m}^{3}$ and $3.0 \times 10^{10}$ particles/ $\mathrm{m}^{3}$ respectively, for Bay-Gon mosquito-coil. The size of particles was observed to be in the range of 0.1 to 1.0 $\mu \mathrm{m}$, with the geometric mean of $0.32 \mu \mathrm{m}$ for Er-Yi mosquito-coil, and $0.31 \mu \mathrm{m}$ for Bay-Gon mosquito-coil.

According to the atove results, the concentrations of aldehydes in a $40 \mathrm{~m}^{3}$ room with various ventilation rates, in where an entire mosquito-coil takes 6 hours to burn out, are calculated as follows:

$$
\ln \frac{\mathrm{G}-\mathrm{Q} \times \mathrm{C} \times 10^{-6}}{\mathrm{G}}=-\frac{\mathrm{Q} \times \mathrm{t}}{\mathrm{V}}
$$

where, $G$ is generation rate in $\mathrm{m}^{3} / \mathrm{hr} ; \mathrm{Q}$, ventilation rate in $\mathrm{m}^{3} / \mathrm{hr}$; , concentration in $\mathrm{ppm} ; t$, time of burning in hour; $\mathrm{V}$, room space in $\mathrm{m}^{3}$. It has been suggested that the general air exchange rate in a residential inhabitant is $0.25-0.5 \mathrm{turn} / \mathrm{hr}$ [18-20], which is equivalent to $10-20 \mathrm{~m}^{3} / \mathrm{hr}$ of ventilation rate in a $4 \mathrm{C} \mathrm{\textrm {m } ^ { 3 }}$ room. In this case, the highest concentrations of various aldehydes will be given as table 2 . The formaldehyde exposure may exceed the TLV-Ceiling ( $0.3 \mathrm{ppm})$, and the highest exposure concentration of acrolein is just within the limit 
of TLV-TWA (0.1 ppm).

Table 2. The estimated indoor concentrations of aldehydes upon burning an entire mosquito-coil in a $40 \mathrm{~m}^{3}$ room with various ventilation rates

\begin{tabular}{lccccc}
\hline & \multicolumn{2}{c}{ Estimated concentration at the indicated ventilation rate, ppm } \\
\cline { 2 - 3 } Aldehyde & \multicolumn{2}{c}{ Er-Yi mosquito-coil } & & \multicolumn{2}{c}{ Bay-Gon mosquito-coil } \\
\cline { 2 - 3 } \cline { 5 - 6 } & $10 \mathrm{~m}^{3} / \mathrm{hr}$ & $20 \mathrm{~m}^{3} / \mathrm{hr}$ & & $10 \mathrm{~m}^{3} / \mathrm{hr}$ & $20 \mathrm{~m}^{3} / \mathrm{hr}$ \\
\hline formaldehyde & 0.26 & 0.16 & & 0.40 & 0.24 \\
acetaldehyde & 0.17 & 0.11 & & 0.14 & 0.09 \\
acrolein & 0.10 & 0.06 & & 0.09 & 0.05 \\
\hline
\end{tabular}

Allethrin was found to occur only in the particulate phase. The amount of particulate-bounded allethrin was $1.68 \mathrm{mg} / \mathrm{gram}$ in Er-Yi mosquito-coil and $0.53 \mathrm{mg} /$ gram in Bay-Gon mosquito-coil (table 1). About 67.1 $\%$ of allethrin present in Er-Yi mosquito-coil was found to be evaporated, while only $26.3 \%$ of allehtrin found in Bay-Gon mosquito-coil was evaporated. It may hence be concluded that, allethrin may not attack the mosquitoes effectively, because all allethrin is sustained in the particulates which are, however, too fine to cohere to insects.

\section{REFERENCES}

1. W.K. Liu, M.H. Wong and Y.L. Mui, Toxic effects of mosquito coil (A Mosquito Repellent) smoke on rats: I. Properties of the mosquito coil and its smoke. Toxicology Letters 39, 223-230 (1987).

2. B.H.O. Azizi and R.L. Henry, The effects of indoor environmental factors on respiratory illness in primary school children in Kuala Lumpur. International Jouranl of Epidemiology 20(1), 144-149 (1991).

3. W.K. Liu and S.E. Sun, Ultrastructural changes of tracheal epithelium and alveolar macrophages of rats exposed to mosquito coil smoke. Toxicology Letters 41, 145-157 (1988).

4. W.K. Liu and M.H. Wong, Toxic effects of mosquito coil (A Mosquito Repellent) smoke on rats: II. Morphological changes of the respiratory system. Toxicology Letters 39, 231-239 (1987).

5. W.K. Liu, T.B. Ng and C.C. Wong, Biochemical and cellular changes in bronchoalveolar lavaged samples from rats after inhalation of mosquito-coil smoke. Toxicology Letters 45, 121-132 (1989).

6. V. Cheng, H.R. Lee and C.S. Chen, Morphological changes in the respiratory system of mice after inhalation of mosquito-coil smoke. Toxicology Letters 62, 163-177(1992).

7. M.V. Moorthy and P.B. Murthy, Ailalysis of sister chromatid exchange, micronucleus and chromosomal aberration frequencies in rodents exposed to mosquito coil smoke by inhalation route. Toxicology Letters 70, 357-362 (1994).

8. R.K. Das, K. Sahu and B.C. Dash, Induction of chromosome aberrations and micronuclei in pulmonary alveolar macrophages of rats following inhalation of mosquito coil smoke. Mutation Research 320, 285292 (1994). 
9. C.H. Wang, Application of dosage technology on insecticides for house-hold uses. The Bulletin of Environmental Health 1, 23-37 (1993) (in Chinese).

10. D.R. Crump and D. Gardiner, Sources and concentrations of aldehydes ketones in indoor environments in the UK. Environment International 15, 455-462 (1989)

11. K.S. Liu, F.Y. Huang, S.B. Hayward, J. Wesolowski and K. Seston, Irritant effects of formaldehyde exposure in mobile homes. Environmental Health Perspectives 94, 91 -94 (1991)

12. D.M. Main and T. J. Hogan, Health effects of low-level exposure to formaldehyde. Journal of Occupational Medicine 25(12), 896-900 (1983)

13. W.D. Kerns, K.L. Pavkov, D.J. Donofrio, E.J. Gralla and J.A. Swenberg, Carcinogenicity of formaldehyde in rats and mice after long-term inhalation exposure. Cancer Research 43, 4382-4392 (1983)

14. R.E. Albert, A.R. Sellakumar, S. Laskin, M. Kuschner, N. Nelson and C.A. Snyder, Gaseous formaldehyde and hydrogen chloride induction of nasal cancer in the rat. Journal of the National Cancer Institute 68(4), 597-603 (1982).

15. R.A. Woutersen, L.M. Appelman, A.V. Garderen-Hoetmer and V.J. Feron, Inhalation toxicity of acetaldehyde in rats.1II. Carcinogenicity study. Toxicology 41, 213-231 (1986).

16. J.M. Patel and E.R. Block, Acrolein-induced injury to cultured pulmonary artery endothelial cells. Toxicology and Applied Pharmacology 122, 46-53 (1993)

17. P.A. Baron, Asbestos and Other Fibers by PCM. In NIOSH Manual of Analytical Methods (4th Edn, Edited by P.M. Eller and M.E. Cassinelli), Method 7400, National Institute for Occupational Safety and Health, Cincinnati, Ohio (Aug. 1994).

18. G.W. Traynor, M.G. Apte A.R. Carruthers, J.F. Dillworth, D.T. Grimsrud, L.A. Gundel. Indoor air pollution due to emissions from wood-burning stoves. Environmental Science and Technology 21, 691697 (1987).

19. C.S. Li, W.H. Lin, FT Jenq. Characterization of outdoor submicron particles and selected combustion sources of indoor particles. A.tmospheric Environment 27, 413-424 (1994).

20. K.W. Tu, E.O. Knutson. Indoor outdoor aerosol measurements for two residential buildings in New Jersey. Aerosol Science and Technology 9, 71-82 (1988) 